\title{
Iniciação Escolar e a Notação Numérica: Uma Questão Para o Estudo do Desenvolvimento Adulto ${ }^{1}$
}

\author{
Maria Helena Fávero² \\ Universidade de Brasília \\ Maria Tereza C. Soares \\ Universidade Federal do Paraná
}

\begin{abstract}
RESUMO - O analfabetismo particulariza uma questão para o estudo do desenvolvimento cognitivo adulto: a interação da aquisição do sistema numérico com os já existentes, as funções evidenciadas e a razão da persistência de erros na notação. Desenvolvemos um estudo junto a dois alunos de alfabetização, 20 e 32 anos. O primeiro reparava bicicletas e o segundo era cobrador de ônibus. Desenvolveu-se dez sessões centradas na mediação da lógica da representação numérica à partir da problematização de situações das experiências pessoais, visando a reestruturação do pensamento e reorientação da atenção nos procedimentos adotados. Os resultados apontam dificuldades na utilização da notação numérica e das regras de cálculo: no estabelecer relações entre a notação das operações e uma situação particular, no reconhecer a sequiência e a composição numérica, no reconhecer que a adição e a subtração são operações que pertencem ao mesmo campo conceitual. Evidencia-se o progresso obtido e discute-se a prática da escolarização de adultos.
\end{abstract}

Palavras-chave: Desenvolvimento cognitivo adulto; iniciação escolar; notação numérica.

\section{Educational Initiation and Numerical Notation: An Issue to be Investigated by the Study of Adult Development}

\begin{abstract}
Illiteracy specifies an issue to be investigated by the study of adult development: the interaction between the acquisition of the numerical system and the pre-existent ones, the verified functions and the reasons for the persistence of notation errors. A study conducted with two students from literacy classes aged 20 and 32 years old is reported. The first student used to fix bicycles and the second was a bus fare-collector . Ten sessions focusing on the logic mediation of numerical representation were conducted. The raising of personal problematic situations was used as a means to restructure thought and orientate the students' attention towards the procedures. The results reveal difficulties to use numerical notation and the rules to calculate; to establish relationships between the notation of operations and a particular situation; to recognize the sequence and numerical composition; to identify that addition and subtraction are operations that belong to the same conceptual field. The progress promoted by the process is shown and the educational practice that adults are submitted to is discussed.
\end{abstract}

Key words: adult cognitive development; school initiation; numerical notation.

Do ponto de vista da Educação Formal uma das conseqüências da chamada Revolução Tecnológica foi a explicitação do papel da matemática nas diferentes áreas de conhecimento.

Em 1986, por exemplo, a Cambridge University Press, publica os anais do encontro da International Commission on Mathematical Instruction (Howson \& Wilson, 1986), realizado no mesmo ano no Kuwait, com o título de "School Mathematics in the 1990s". Esta publicação gira em torno da defesa da tese geral, segundo a qual, uma vez que a matemática fundamenta a tecnologia em todas suas manifestações, e a política que determina o uso desta tecnologia, en-

1 Parte deste trabalho foi desenvolvido durante a estadia da $1^{\text {a }}$ autora como Professora Visitante no Programa de Pós-Graduação em Educação da Universidade Federal do Paraná. A continuação da pesquisa tem apoio do CNPq.

2 Endereço: Universidade de Brasília - Instituto de Psicologia - CEP.: 70.910-900 Brasília, DF. E-mail: faveromh@unb.br tão o ensino da matemática deveria, deliberadamente, ser relacionado com estas questões.

No entanto, e apesar deste discurso ser hegemônico, o acesso à matemática no nosso país, se considerarmos tão somente o número significativo de analfabetos, é absurdamente limitado. Fora isto, sabemos, de trabalhos anteriores, que os adultos que chegam à escola, têm dificuldade para serem aprovados, sendo este um dos motivos de repetência e evasão. Esta é a questão central deste trabalho: o ensino da matemática, ao adulto em processo de alfabetização.

Como assinala Kleiman (1998), o impacto do letramento em países onde um grande segmento da população não lê ou escreve, apenas começa a ser entendido.

Em meio a esta polêmica discussão, no final dos anos 80, Tulviste analisando os resultados de vários grupos de pesquisa, conclui que em determinadas atividades, o pensamento científico, abstrato, também pode ser encontrado em sociedades iletradas, e defende que a visão dualística de unidades de pensamento (lógico, abstrato, versus concreto) baseia-se numa concepção falsa de que os indivíduos numa 
sociedade industrializada e letrada pensam de uma maneira consistentemente lógica e formal, ignorando-se o fato de que as populações letradas mantêm formas de pensamento mítico e concreto ao lado do pensamento lógico e abstrato.

Para este autor, uma vez que admitimos que a atividade da qual o pensamento emerge é sempre heterogênea, então também o pensamento é heterogêneo, sempre, independente da época ou da cultura, tanto entre como intra-indivíduos. Este ponto de vista é defendido, implícita ou explicitamente por autores como Wertsch (1991), Valsiner (1989) e Oliveira (1992, por exemplo), e pode-se afirmar que esta idéia da heterogeneidade do pensamento é reconhecida há muito tempo nas ciências da cultura, e também não é nova na Psicologia, mas isto não significa que ela tem sido considerada na pesquisa.

Particularmente, em relação à aprendizagem da linguagem matemática, uma mudança metodológica para o acesso à cognição do analfabeto, permitiu, à partir dos anos 80 , o desenvolvimento de estudos que procuraram provar que mesmo sem o acesso a uma linguagem matemática acadêmica, os analfabetos pensam lógica e abstratamente. No Brasil, esta foi a tônica dos trabalhos pioneiros de Carraher, Carraher \& Schiemann, (1982; 1983; 1985, citados em De Lima \& Fávero, 1998).

Considerando a relação entre o desenvolvimento psicológico adulto e o acesso à diferentes sistemas de significação a questão que se coloca é, portanto, a seguinte: no que culturalmente se constitui e significa a atividade de leitura destes diferentes sistemas, e quais formas de pensamento esta atividade engendra? A idéia é, portanto, aquela de que uma atividade engendra um tipo específico de pensamento. Ora, considerá-la, então, na pesquisa junto aos adultos iletrados, significa adotar uma abordagem genética, desenvolvimental, ou, em outros termos, significa investigar o potencial mediacional da linguagem escrita, como instrumento, isto é, investigar como os sistemas simbólicos ao serem adquiridos interagem com os sistemas já existentes e que funções se evidenciam.

Guiados por esta questão, Fávero \& De Lima se propuseram a trabalhar com a articulação entre a tipologia do texto, conforme proposta por Luria (1981) e a semiótica de Lotman (1988 a e 1988b), que elabora a proposição dos sistemas simbólicos como subtextos no texto mais amplo da cultura. Foi estudado a aquisição da linguagem escrita, a partir da produção de cartas, por um adulto de 19 anos, na época, recentemente emigrado da região nordeste para Brasília. O processo de aquisição foi estudado através da análise da sua produção de texto, da interação no processo de escrita e nas representações do sujeito sobre este processo (Fávero \& De Lima, 1989; De Lima \& Fávero,1998).

As autoras consideraram que houve uma grande variedade de funções e potenciais dialógicos envolvidos, todos carregados de significados socialmente constituidos. Afirmaram ainda, que trabalhando com significantes lidos e escritos, o sujeito se engajou num processo de reflexão que criou instrumentos internos de amplificação e organização de informações através das cartas. Dito em outros termos: o sujeito se comunicava não apenas com sua família, mas consigo mesmo, e assim, ampliou sua interação com o universo das representações letradas.

Retornando para a linguagem específica da matemática, embora vários estudos, como já citamos antes, tenham demonstrado que, o fracasso escolar dos adultos em início de escolarização, não corresponde à sua verdadeira capacidade de manejar o raciocínio lógico e determinados conceitos matemáticos em determinadas situações, a escola continua a reprová-los, e a considerá-los incapazes, o que trás à tona, a questão da competência prévia, que no caso dos adultos, está estritamente relacionada ao trabalho.

Duas questões podem então ser levantadas:

1. Até que ponto o fato de se reconhecer esta capacidade de manejar o raciocínio lógico está deixando para a escola apenas o papel de valorizar as estratégias próprias de resolução do adulto em detrimento do acesso a uma linguagem específica e própria de um sistema lógico?

2. Porque apesar da assimilação desse discurso, de modo geral, as professoras que trabalham com classes de alfabetização de adultos, queixam-se da dificuldade que eles apresentam com as operações matemáticas, e explicam esta dificuldade considerando haver um déficit cognitivo, justificando a evasão e a repetência (Fávero \& Col., 1995)?

As pesquisas recentes sobre a trajetória do desenvolvimento intelectual na vida adulta, apontam para a importância da combinação de aquisição de habilidades individuais e contextos ambientais favoráveis, incluindo as oportunidades educacionais. Estas vantagens, ocorrendo cedo na vida, facilitam, segundo as pesquisas, o desenvolvimento de um estilo de vida adulta caracterizado por um alto status ocupacional e um meio social mais complexo com oportunidades variadas de estimulação intelectual. Nesse meio, as habilidades intelectuais são constantemente requisitadas, praticadas e reforçadas, resultando no desenvolvimento e manutenção de altos níveis de habilidade intelectual até a idade mais avançada (ver, por exemplo, Arbucckle, Maag, Pushkar \& Chaikelson, 1998).

Por mais controversa que possa ser esta questão, e ao mesmo tempo, por mais cuidado que se possa ter na discussão das implicações do anafabetismo, o fato parece ser que, a exclusão de milhões de brasileiros da escola, seja pelo não acesso, seja pela repetência e evasão, instala um círculo vicioso no qual a ausência da escolaridade institucionalizada, considerada como a instância de aquisição de habilidades básicas num mundo letrado, acaba comprometendo o desenvolvimento pessoal, já que ela compromete o acesso a ocupações que exigem habilidades intelectuais, e restringe os analfabetos a ocupações braçais. Não se trata de desqualificar o sujeito excluido da escola; trata-se de apontar um equívoco: não é possível analisar o desenvolvimento psicológico de um ponto de vista do contexto sócio-histórico, ignorando o papel da instituição escolar num contexto no qual ela, além da mediação de conhecimento, regula a inserção e a mobilidade social.

É deste ponto de vista que, Fávero e Coll. (1998), desenvolveram um estudo centrado na resolução de problemas arit- 
méticos do tipo escolar, do qual participaram 10 sujeitos, sendo 5 homens e 5 mulheres, alunos de classes de alfabetização do Curso Supletivo de uma escola da Fundação Educacional do DF. Cada um destes casais freqüentava uma série diferente: nivelamento ou alfabetização, $1^{\mathrm{a}}, 2^{\mathrm{a}}, 3^{\mathrm{a}} \mathrm{e} 4^{\mathrm{a}}$ séries. O critério para escolha destes sujeitos foi a indicação, pelas professoras dos alunos que apresentavam maior dificuldade na aprendizagem de matemática. Estas mesmas professoras foram submetidas a uma entrevista semi-estruturada segundo três eixos básicos: as disciplinas escolares de maior e menor dificuldade de aprendizagem dos adultos; a explicação para a dificuldade de aprendizagem; a comparação no desempenho escolar de homens e mulheres. De acordo com uma coleção de provas previamente coletadas junto às professoras, dois protocolos foram construídos, que, salvo pequenas diferenças de uma série para outra, seguiam um mesmo padrão: problemas que envolviam as operações de adição e/ou subtração na sua resolução; resolução de adições e subtrações; composição e decomposição de números; indicação do sucessor e do antecessor numérico. Um dos protocolos era apresentado oralmente e o outro, por escrito, em sessões individuais e em dias consecutivos. Após a realização do protocolo escrito, cada sujeito era submetido a uma entrevista, na qual lhes era solicitado descrever seus procedimentos de resolução. Todas as sessões (2 para cada sujeito, num total de 20 sessões) foram registradas em áudio e transcritas na íntegra.

Os resultados mostraram que nas operações o mais freqüente, é uma tentativa de:

1. seguir uma determinada regra de notação da operação, com a utilização de números e traço. Por exemplo, na resolução do problema Roberto tem cinco apontadores. Renata tem quatro. Quantos apontadores têm os dois juntos? A solução escrita dada por um dos sujeitos ( $1^{\mathrm{a}}$ série, supletivo, sexo feminino, 17 anos, doméstica) foi:

$$
\frac{5+4}{8}
$$

2. somar apenas os valores absolutos dos algarismos que compõem os números. Por exemplo, na operação

$$
\begin{array}{r}
30 \\
+15 \\
\hline
\end{array}
$$

um dos sujeitos (nivelamento, supletivo, sexo masculino, 19 anos, vigia) responde oralmente: "três com zero, aí fica três... três com cinco, oito, com um, nove".

3. agregar um número no outro independente do sinal da operação. Por exemplo:

\section{0}

$-4$

o mesmo sujeito do exemplo 1 escreve 1004 como resposta, e explica oralmente: "Eu peguei o um, o zero e o quatro, né? ...Eu peguei o quatro, né? Depois os dois zero e o um".

4. operar com os valores absolutos dos algarismos observando a ordem decimal na qual aparecem, chegando ao resultado correto. A explicação oral, porém, demonstra não compreensão da composição do número. Por exemplo para a operação

um sujeito também da $1^{\text {a }}$ série escreve 255 como resposta, e verbaliza a seguinte explicação: "Eu peguei, e desci o cinco. Eu tenho o quatro, como mais um, é cinco. Tenho um, com mais um é dois. Dois, dois e vinte e cinco".

5. uma tentativa de seguir uma determinada regra para operar com números. Por exemplo: na adição

$$
\begin{array}{r}
15 \\
+\quad 11 \\
\hline
\end{array}
$$

o sujeito verbaliza "coloco dez em cima do quinze, fica vinte, vinte e cinco, aí dá dois, eu fico com vinte e sete reais

6. operar com números, não respeitando a ordem posicional de seus algarismos. Por exemplo, na resolução do problema Na primeira gaveta da mesa tem 160 folhas e na segunda, 49. Nas duas gavetas juntas, quantas folhas têm? A resolução de um dos sujeitos (4a série, supletivo, sexo feminino, babá) foi 170 verbalizando: "Eu abaixei o zero, né? Sete mais nove dá 16 ".

De um modo geral, o desempenho dos sujeitos foi muito baixo, em ambas as situações, escrita e oral, repetindo-se os mesmos tipos de erros já amplamente descritos nas pesquisas com crianças, e confirmando o que é defendido por Nunes (1997) sobre o papel diretor e limitador dos sistemas de signos. Segundo esta autora, existem erros específicos que podem ser esperados pelo fato do sujeito utilizar um sistema específico de signos. O alinhamento das colunas, colocando um número embaixo do outro de mesma ordem é um exemplo disto.

Segundo diversos autores (Meissner 1986, por exemplo) estes tipos de erros são baseados em regras, ou seja, derivam de procedimentos padronizados de resolução, ditados pelo meio escolar.

A questão então é: porque adultos, que desempenham competentemente certas atividades usando certos recursos do raciocínio matemático, apresentam estes tipos de erros? Seria possível desenvolver um processo de mediação da reconstrução individual das ferramentas culturais da aprendizagem e do pensamento, à partir da reestruturação das experiências pessoais ? Seria possível se desenvolver um procedimento de intervenção junto a adultos com dificuldades de aprendizagem de matemática, centrado nesta mediação? Estas foram as questões que fundamentaram o estudo que aqui relatamos.

\section{Método}

Deste estudo participaram dois sujeitos, de 20 e 32 anos, respectivamente, apontados pelas professoras como os alunos de maior dificuldade de aprendizagem da matemática, sendo o primeiro aluno do $1^{\circ}$ ciclo $\left(1^{\mathrm{a}} \mathrm{e} 2^{\mathrm{a}}\right.$ séries $)$ e o segundo do $2^{\circ}$ ciclo ( $3^{\mathrm{a}}$ e $4^{\mathrm{a}}$ séries) de alfabetização de adultos, de uma 
escola da Rede Municipal de Ensino de Curitiba, Paraná. O primeiro sujeito, nomeado daqui para frente como sujeito $\mathrm{A}$ viveu até os 16 anos na zona rural, em município distante aproximadamente $150 \mathrm{~km}$ de Curitiba, onde trabalhava em atividade braçal na roça. Nos últimos quatro anos ele tem vivido em Curitiba e na época do estudo trabalhava em uma oficina consertando bicicletas. Segundo seu relato até dois anos antes do estudo não tinha nenhum histórico de escolaridade.

O segundo sujeito, nomeado daqui para frente como sujeito $\mathrm{D}$, é oriundo de município de porte grande, distante aproximadamente $100 \mathrm{~km}$ de Curitiba, com população em torno de 500.000 habitantes. O sujeito relata ter desenvolvido várias atividades, entre elas ter sido "bóia-fria" e conferente de mercadoria. Na época do estudo declarou ser cobrador de ônibus em linha urbana do município de Curitiba há 5 anos.

Neste estudo, procedeu-se, a uma intervenção, desenvolvida em 10 sessões individuais de 50 minutos cada, centradas no mesmo conteúdo descrito acima para as provas do estudo anterior: a numeração. Nessas sessões procedia-se ao tutoramento dos sujeitos na compreensão e elaboração da notação do sistema numérico, através de operações envolvendo os diferentes sistemas de medida e uso do número como código numérico. Em outros termos, nos baseamos na proposição de Büchel (1995), de mediar a reconstrução individual dos instrumentos culturais da aprendizagem e do pensamento, a partir da reestruturação das experiências pessoais.

Para tanto, partiu-se sempre das noções que o sujeito considerava ter conhecimento e solicitava-se que ele registrasse esse conhecimento, por escrito, em folha de papel. Esse registro, através do desenvolvimento de determinadas atividades era checado em relação aos princípios da lógica de notação do sistema numérico. Pressupunha-se com isso, como Carlson e Wiedl (1995) que houvesse a reestruturação dos processos do pensamento e a reorientação da atenção do sujeito e dos procedimentos que ele empregava para chegar à solução do problema apresentado. Ou seja, esperava-se que o sujeito tomasse consciência dos princípios da lógica de notação numérica, assim como, das eventuais diferenças entre esse princípios e a notação por ele produzida.

Estas sessões foram desenvolvidas por uma de nós, e registrada pela outra, através de observação livre e áudio. Essas observações e as transcrições dos registros na sua íntegra, permitiram a análise da compreensão e elaboração do sistema numérico assim como a análise das interações durante o tutoramento.

\section{Resultados e discussão}

Apresentamos a seguir, e separadamente, os resultados obtidos com cada um dos sujeitos, para depois compará-los e discuti-los.

\section{Sujeito A}

Quando solicitado a escrever o que já conhecia, o sujeito A declarou que faria uma soma, e registra

$$
\begin{array}{r}
235 \\
-\quad 115 \\
\hline
\end{array}
$$

Ao ser indagado a respeito do sinal - , o sujeito disse tratar-se de um ponto, e quando questionado a respeito do sinal da soma, ele registrou o sinal $\mathrm{x}$.

Ao ser informado que o sinal - refere-se a uma subtração ("conta de menos") o sujeito efetuou corretamente a operação. Ao ser solicitado, então, que criasse um problema para ser resolvido com a mesma conta, o sujeito declarou não conseguir.

Com base na mesma operação, foi apresentado oralmente, então, o seguinte problema para o sujeito: "Uma pessoa ganha 235 reais e gasta 115 para pagar o aluguel. Com quanto esta pessoa ficou?" Diante da pergunta: "sobrou dinheiro para a pessoa?", o sujeito afirmou "sobrou", mas disse ter sobrado 15 reais. Mesmo voltando à operação acima, o sujeito não relacionou o resultado desta com o problema criado.

Ou seja: o sujeito parecia saber notar alguns números e usar determinadas regras de cálculo, mas não demonstrava identificar os sinais das operações com as operações a serem realizadas, e não demonstrava saber estabelecer relações entre a notação das operações e uma situação de problema. Ou seja: ele não só apresentava dificuldade no reconhecimento da notação convencional, como também apresentava dificuldade em perceber esta notação como forma de registrar situações que podiam ser quantificadas.

Do mesmo modo o sujeito demonstrou ter dificuldade em reconhecer e nomear a seqüência numérica, sobretudo a partir da centena.

Por exemplo, na operação

$$
\begin{array}{r}
125 \\
+312 \\
\hline 437
\end{array}
$$

o sujeito leu oralmente as parcelas de modo correto, mas leu o resultado da seguinte forma: " quatrocentos, trezentos, e sete". Quando solicitado a decompor este mesmo número, através da operação

$$
\begin{array}{r}
400 \\
+\quad 30 \\
\hline
\end{array}
$$

o sujeito não deu uma resposta.

O sujeito foi solicitado, então, a ler a composição do mesmo número através de números de um, dois e três algarismos: de 1 a 10 , de 10 a 100 e de 100 a 1000 . O sujeito demonstrou não conhecer a seqüência numérica, e sua nomeação, a partir do 200, lendo: "cem, duzentos, quatrocentos, trezentos". Ou seja: o sujeito não tinha consciência de que a sequiência numérica na unidade, na dezena e na centena, era a mesma. Ou em outros termos: o sujeito não tinha consciência de que o número de agrupamentos podia ser o mesmo, embora a unidade destes agrupamentos variasse.

Com quatro pedaços iguais de papel, divididos de uma mesma folha, propôs-se, então ao sujeito, uma simulação de quatro notas de 100 reais cada. Estas notas foram entregues ao sujeito, uma a uma, solicitando-lhe que representasse por 
escrito, de diferentes modos, a composição das centenas formadas. De posse de 2 notas, o sujeito escreveu 200, mas apresentou dificuldade de registrar a composição de 200 através da soma de duas parcelas de 100, e esta dificuldade foi maior, quando se tratava de quantidades superiores. No entanto, seguindo-se este mesmo procedimento, e decompondo mais uma vez a centena, o sujeito agrupou os 400 .

Ou seja: o sujeito A apresentava dificuldade em incluir as quantidades menores nas maiores, ou em outros termos, ele parecia desconhecer a regra numérica, segundo a qual, um número posterior da sequiência numérica, é formado pela composição dos números anteriores na seqüência. Mas, quando criada uma situação que lhe facultasse perceber a regra numérica, ele realizou o agrupamento.

Nas outras sessões com o sujeito A, o mesmo procedimento foi mantido variando-se as situações. As regras de composição da sequiência numérica foram discutidas com apoio em calendários e instrumentos de medida de comprimento (régua e fita métrica). Ao fim das sessões pode-se observar um avanço do sujeito A na compreensão da adição $1+1 ; 10+10 ; 100+100$, evidenciado, principalmente, na explicação de como compôs um mês do calendário e de como confeccionou uma fita métrica e uma linha do tempo.

\section{Sujeito D}

O sujeito D afirmou logo no primeiro contato, ter dificuldades com a divisão, repetindo o que sua professora nos havia dito. Para justificar sua dificuldade o sujeito D dizia "eu tava com esquecimento de conta". Quando solicitado a escrever uma, ele escreveu a operação 9659 : 50 e leu: “ noventa e seis, cinqüenta e nove, por cinqüenta". Questionado sobre esta leitura, o sujeito disse saber que estava errado, embora ninguém tivesse lhe dito isto, e se justificou assim: "é um desligamento".

O modo de leitura usado pelo sujeito foi então discutido com ele, como sendo usual para a leitura de números enquanto códigos numéricos, dando-se exemplos (Número de $\mathrm{CPF}$, telefone, registro de nota fiscal, etc.), mas o sujeito demorou a aceitar que este era um modo possível de leitura, insistindo que este era um modo errado.

Ao ser indagado sobre os números com os quais ele lidava no seu dia-à-dia de trabalho, o sujeito escreveu números hipotéticos que ele costumava ver na catraca do ônibus, e anotar numa ficha, ao iniciar e finalizar seu período de trabalho: Início 096385 (chegada)

Final 099731 (fim)

Aproveitando estes dados, foi perguntado ao sujeito como ele faria para saber quantas pessoas haviam passado pelo ônibus durante o seu período de trabalho como cobrador. $\mathrm{O}$ sujeito respondeu de imediato: "somar, é lógico". O sujeito então soma os dois números, encontrando 196116, e continua a achar que a resolução está correta. Foi solicitado então ao sujeito, que ao número inicial (096385) ele adicionasse uma unidade, e lhe foi perguntado se o número encontrado era então o número de pessoas depois de ter entrado uma pessoa. Ele assentiu . O mesmo foi feito em relação a adição de uma dezena. $\mathrm{O}$ sujeito novamente assentiu, mas continuou a não percebe que o significado do registro numérico da catraca, não correspondia ao número de pessoas que entraram no ônibus naquele período de tempo, e sim , a um registro cumulativo.

Voltando aos números iniciais acima, foi lhe então perguntado como ele poderia determinar o número de pessoas que entraram no ônibus, a partir do número registrado no início e o registrado no final. O sujeito então responde, olhando para uma de nós, e fazendo referência à pesquisadora que havia lhe colocado a questão: "Ah! Já sei onde ela quer chegar. É de diminuir!” E o sujeito registra uma subtração mantendo os números na ordem que eles aparecem na catraca, ou seja, mantém a notação acima. $\mathrm{O}$ sujeito não leva em consideração que o segundo número deveria ser o minuendo e não o subtraendo, mas resolve a operação aplicando as regras para subtração "com empréstimo", como se estivesse reagindo apenas ao estímulo visual dos números registrados um embaixo do outro, sem levar em conta a situação que originou a questão proposta. Por isto mesmo, como o que ele considerou o minuendo é um número menor do que o que ele considerou como subtraendo, então ao chegar na ordem maior do número, e deparar com a situação de 9 para chegar a 8 , ele registra 0 , como resposta para a impossibilidade de solução:

096385

$\underline{099731}$

06654

Questionado sobre este resultado, o sujeito argumentou: "falta tirar os vale transporte". Esta resposta denotou, mais uma vez, sua incompreensão da adição e subtração como operações que pertencem ao mesmo campo conceitual (Verganud, 1991).

O sujeito só modificou seu procedimento quando questionado se naquele dia, por exemplo, ele considerava que havia passado aproximadamente aquele número de pessoas pela catraca durante seu período de trabalho. Aí então, o sujeito percebe que sua resposta é impossível, volta à conta e a refaz.

Nas sessões seguintes o sujeito D manifestou grande interesse pelas operações inversas e reiterando sua dificuldade com a linguagem matemática, solicitou inclusive, que fossem discutidas as regras que indicam a ordem de resolução das operações em uma expressão numérica por ele apresentada. Quando discutimos com ele as relações entre as operações, que estão subjacentes às regras que são impostas como modo único de resolução das expressões numéricas, surpreendeuse de que houvesse uma explicação para a resolução das operações em uma certa ordem. Mais surpreso ficou, com a possibilidade de escrever uma situação-problema tendo como referência os números e as operações da expressão numérica por ele escrita.

Apesar do número reduzido de sessões, pode-se observar um avanço do sujeito $D$ na compreensão das relações entre operações e de que um mesmo problema pode ser resolvido por diferentes operações, e uma mesma operação pode gerar diferentes problemas. 
Os resultados obtidos junto aos dois sujeitos nos autoriza a afirmar que ambos apresentavam incompreensão das regras da lógica de notação do sistema numérico e isto pode ser observado mesmo em relação àquelas noções que eles afirmavam ter conhecimento. Podemos afirmar então, que, o problema central destes alunos apontados pelas professoras como portadores de dificuldades na aprendizagem da matemática, era a incompreensão do sistema numérico em si, e, consequentemente sua notação, o que lhes dificultava o manejo das operações. Como no trabalho anteriormente citado, os sujeitos A e D também procuravam aplicar certas regras, que na sua concepção deveriam estar memorizadas, como a referência do sujeito D ao "esquecimento".

Em outros termos, podemos dizer, face a estes resultados e dos trabalhos anteriores já citados (Fávero \& Coll., 1998; Fávero, 1999), que a escola ao propiciar a aquisição do sistema representacional numérico, fornece apenas certas regras para as operações, do tipo "fazendo assim dá certo", sem fazer referência ao significado da notação.

A notação sempre se constituiu num problema particularmente complexo no estudo do desenvolvimento cognitivo. Numa revisão recente, Lee \& Karmilloff-Smith (1996) analisaram o desenvolvimento dos limites cognitivos nas notações, e exploraram, na criança, a relação interativa dinâmica entre a notação e a representação, fazendo uma diferenciação entre a "representação" e a "notação", sendo o primeiro termo usado em referência ao que é interno na mente dos indivíduos e o segundo, para o que é externo a ela, retomando as propostas de Godman (1976, citado em Lee \& Karmillof-Smith, 1996).

Um dos aspectos importantes que estes pesquisadores trazem em sua revisão e análise, é a distinção entre o que eles denominam de notações de tarefas que envolvem estados de transição, das notações que envolvem estados de transformação. Discutindo os resultados de uma pesquisa envolvendo estes dois tipos de tarefas, os autores salientam que : "o desenvolvimento da notação na criança envolve uma progressiva mudança de um desejo de reproduzir fielmente todos os estados da tarefa, para o entendimento da necessidade de codificar informações cruciais sobre as transformações de um estado para o seguinte" (p. 23, grifo nosso). Além disto, os autores salientam que, todas as crianças tinham uma representação interna adequada da resolução da tarefa, uma vez que elas conseguiam resolvê-la e repeti-la corretamente várias vezes, mas este fato não garantia que isto fosse "traduzido" em suas notações, e concluem: " a notação envolve muito mais do que uma mera externalização de representações internas. De fato, nosso estudo tem salientado o fato de que a relação entre representação e notação é complexa. Embora as notações superem as limitações da mente a nível da memória, da comunicação, etc., e funcionem como um meio para superar nossas limitações biológicas, a aquisição da competência na notação coloca uma série de novos problemas cognitivos para a criança em crescimento, tornando-se um marco fundamental no desenvolvimento posterior" (p.22).

Em relação à matemática na escola, já há algum tempo, existe um consenso entre os pesquisadores para o fato de que, mesmo propiciando aos alunos extensa experiência com materiais concretos e modelos manipuláveis, antes de iniciar a representação simbólica, dois pontos deveriam ser considerados: 1/ os alunos não ultrapassam facilmente a "distância" que parece haver entre o modelo concreto e a representação simbólica (ver Resnick, por exemplo,1982); 2/ os alunos apresentam maneiras idiossincráticas e individuais de interpretar modelos concretos, maneiras estas que podem estar em conflito com os procedimentos padrões usados (e demonstrados) pelo professor na sala de aula (Carpenter e Moser, 1983). Uma das estratégias defendidas pelos autores citados é a de tornar as experiências de aprendizagem na escola, o mais próximas possíveis do contexto mais amplo em que o aluno vive fora da escola, sob o aspecto sócio-linguístico e cultural, de forma a possibilitar o questionamento de natureza epistemológica, por parte do aluno. Nosso procedimento mostrou que isto também é possível com adultos.

\section{Conclusão}

Os dados que obtivemos juntos aos sujeitos que participaram deste estudo, assim como junto aos sujeitos dos outros estudos já citados, nos leva a concluir que a escola não trabalha com a possibilidade do sujeito formar representações identificáveis; a escola ignora isto, e o sujeito acaba sobrepondo representações. Ou seja, não lhe é facultado um tratamento dos dados que ele dispõe; há uma imposição de regras: "tem que ser assim".

Na verdade, por trás destas questões de escolarização está a relação entre conceitos e os sistemas de signos usados no pensamento e na comunicação. Não se trata, portanto, de algo trivial, uma vez que a elas articula-se inúmeras implicações relacionadas particularmente com o desenvolvimento adulto, como por exemplo, a questão do desempenho profissional, a questão da formação continuada, e à uma questão geral, que está na base destas outras, que é aquela relacionada ao conceito de competência. Defender a capacidade cognitiva destes sujeitos, enquanto o sistema educacional os considera incompetentes, acarretando consequiências negativas para seu desenvolvimento profissional, é o mesmo que criar um impasse, que paralisa a questão.

Este trabalho foi desenvolvido no âmbito do Projeto de Pesquisa - Desenvolvimento Cognitivo Adulto e a Iniciação à Matemática: a Resolução de Problemas e a Notação das Operações (CNPq) - que está em desenvolvimento. No entanto, os dados obtidos em estudos anteriores (Projeto de Pesquisa - Oficina do Conhecimento, relatório CNPq, 1998; Fávero, 1999) e aqueles apresentados neste estudo, nos permitem algumas considerações à título de conclusões.

A inserção do indivíduo, seja criança, adolescente ou adulto, pressupõe a interação deste indivíduo com os instrumentos de representação do conhecimento humano já convencionados. No início da escolarização, e independente da faixa etária, temos dois instrumentos privilegiados: aqueles referentes ao letramento, isto é, os da leitura e escrita e aqueles referentes à numeração. Neste artigo privilegiamos o segundo, procurando analisar como o meio escolar 
lida com estes instrumentos em relação ao adulto, e como é possível construir um outro procedimento para isto.

Nossos dados sugerem que o meio escolar interage com representações particulares elaboradas sobre este sistema de representações da numeração, interação esta, viabilizada através de regras referentes ao sistema numérico, que não efetiva a mediação do sistema em si, o que pode ser observado por exemplo pelo registro dos exercícios resolvidos nos cadernos dos alunos. Ou seja: a escola internaliza e domina o uso de determinadas regras referentes ao sistema numérico, regras estas que têm um significado apenas em relação ao contexto e negociação escolar, e não em relação ao uso do sistema numérico. Como no contrato pedagógico a professora detém o saber e determina como mediá-lo, então a mediação se dá via regras, porque este é o próprio procedimento dela, uma vez que como vimos, no geral, a professora se restringe a estas regras, não interagindo com a lógica de formação dos sistemas numérico e de medidas, ensinados pela escola. Ou seja: nem as professoras, nem os alunos, sejam estes, adultos ou crianças, interagem com o modelo lógico do sistema numérico. A prática das professoras, através de regras, se dá via vetor professora-aluno, mantendo esta nãointeração, e ao mesmo tempo protege-a de qualquer confronto dela mesma com este sistema lógico.

Entre tantas, temos uma importante implicação do ponto de vista psicológico: o não acesso do sujeito a um sistema lógico, aliás a um dos que governam nossas práticas sociais - o sistema lógico da numeração, este mesmo no qual se baseia a computação, e que está na base de tudo que diz respeito a valores (transações comerciais), representações gráficas quantitativas (eleições por exemplo), e assim por diante, e que tem, portanto, uma implicação importante para a prática da cidadania.

Finalmente, cabe concluir sobre a pertinência do procedimento proposto. Trata-se de um meio de efetivamente considerar aquilo que o sujeito já trás como construído. Também é um meio de evidenciar a relação entre a atividade desenvolvida pelo sujeito e o tipo de pensamento engendrado, tanto do ponto de vista da atividade desenvolvida fora da escola, no trabalho, como naquela proposta e desenvolvida em sala de aula (ver, por exemplo, Soares, 2000 a; Soares, 2000 b).

\section{Referências}

Arbuckle, TY; Maag, U.; Pushkar, D.; Chaikelson, JS (1998) Individual Differences in Trajectory of Intellectual Development. Psychology and Aging, vol. 13, no. 4, 663-675.

Burton, L. (1984) mathematical Thinking: the struggle of meaning. Journal for Reaserch in Mathematics Education, n.1, pp. 35-49.

Büchel, FP (1995) De la métacognition à l' éducation cognitive. Dans: FP BUCHEL (org.), L' éducation cognitive, Neuchatel/ Paris: Delachaux et Niestlé, p. 9-44.

Carlson \& Wiedl (1995) Principes d' évaluation dynamique: l'application d'un modèle spécifique. Dans: FP BUCHEL (org.), L' éducation cognitive, Neuchatel/ Paris: Delachaux et Niestlé, 215- 238.
Carpenter, T.P., \& Moser, J.M. (1983) The acquisition of addition and subtraction concepts. In: R. Lesh \& landau (Eds.), Acquisition of mathematical concepts and process (pp.7-44) New York: Academic Press.

De Lima, S.G. \& Fávero, M.H. (1998) Learning to write letters: semiotic mediation in literacy accquisition in adulthood. In: M. Kohl de Oliverira \& J. Valsiner (Eds.) Literacy in Human Development (pp.247-279) Stanford: Ablex Publishing Corporation.

Fávero, M.H. \& De Lima, S.G. (1989) A produção de texto por um migrante da zona rural: um estudo de caso. XIX Reunião Anual de Psicologia, Ribeirão Preto, S.P.

Fávero, M.H. \& Coll. (1995) Ensinar e aprender: o conhecimento na escola. XXV Reunião Anual de Psicologia. Ribeirão Preto, S.P.

Fávero, M.H.; Ferraz da Rocha, R.; Souza, JC (1998) O desempenho de homens e mulheres frente a problemas de matemática: um estudo desenvolvido no supletivo do $1^{\circ}$ Grau. Em: VI Encontro Nacional de Educação Matemática. Resumos. São Leopoldo, RS, UNISINOS, V.02, p. 336.

Fávero, M.H. (1999) Desenvolvimento cognitivo adulto e a iniciação escolar: a resolução de problemas e a anotação das operações. Apresentado em Simpósio na XXIX Reunião Anual de Psicologia, Campinas, SP.

Howson, G; Wilson, B. (Edts.) (1986) School Mathematics in the 1990s. Cambridge, GB: Cambridge University Press.

Kleiman, A.B. (1998) Schooling, Literacy, and Social Change: Elements for a Critical Approach to the Study of Literacy. In: Marta Kohl de Oliveira \& J. Valsiner (Eds.) Literacy in Human Development. Stanford: Ablex Publishing Corporation, pp.183225.

Lee, K. \& Karmiloff-Smith, A. (1996). The development of cognitive constraints on notations. Archives de Psychologie, 64, pp. 3-26.

Lotman, Y.M. (1988 a) The semiotics of culture and the concept of a text. Soviety Psychology, XXVI (3), pp.52-58.

Lotman, Y.M. (1988 b) Text within a text. Soviety Psychology, XXVI (3), pp. 32-51.

Luria, A.R. (1981) Language and cognition. J. Wersth (Ed.) New York: Wiley.

Meissner, H. (1986) Cognive conflits in mathematics learning. European Journal of Psychology of Education, 1, n.2, pp.7-15.

Nunes, T. (1997) Systems of signs and conceptual knowledge. In: T. Nunes \& P.E. Bryant (Eds.) Learning and Teaching Mathematics: na Integrational Perpective. Hove, United Kingdon: Psychology Press, pp.29-44.

Oliveira, M.K. (1998) Conceptual Organization and Schooling. In: M. Kohl de Oliveira \& J. Valsiner (Eds.) Literacy in Human Development, Stanford: Ablex Publishing Corporation, pp.227245.

Resnick, L.B. (1982) Syntax and semantics in learning to subtract. In: T.P. Carpenter, J.A. Moser \& T. A. Romberg (Eds.) Addition and Subtraction: A Cognitive Perspective. Hillsdale, N.J: Lawrence Erlbaum Associates.

Schaie, K.W. (1994) The course of adult development. American Psychologist, vol. 49, n. 4, pp.304-313. 
Soares, M.T.C. (2000 a) O professor das séries iniciais do ensino fundamental e o saber escolar de matemática: mediando a aprendizagem de seus alunos e de seus pares. Anais do III Congresso Brasileiro de Psicologia do Desenvolvimento, 13-15 de julho, Niterói, RJ.

Soares, M.T.C. (2000 b) Práticas discursivas nas aulas de matemática das séries iniciais do ensino fundamental: os professores, seus saberes e a criação de situações didáticas. Cadernos de Resumos da III Conferência de Pesquisa Sócio-Cultural, 17-21 de julho, Campinas, SP.

Tulviste, P. (1989) Education and development of concepts in adults with and without schooling. Soviet Psychology, XXVII (1), pp.5-21.

Yussen, S.R. (1985) The role of metacognition in contemporary theories of cognitive development. In: D.L. Forrest-Pressley,
G.E. Mackinnon \& T. Gary Waller (Eds.) Metacognition, Cognition, and Human Performance, Volume 1, pp.253-283. Valsiner, J. (1989) Human development and culture. Lexington, MA: Lexington Books.

Valsiner, J. (1989) Human development and culture. Lexington, MA: Lexington Books.

Vergnaud, G (1991) L'appropriation du concept de nombre: un processus de longue haleine. In: J.Bideau; C. Meljac et JP Fisher (Édts.) Les chemins du nombre. Lille, France: Presses Universitaires de Lille, p. 271-282.

Wertsch, J. (1991) Voices of minds: a social-cultural approach to mediated action. Cambridge, MA: harvard University Press.

Recebido em 09.05.2001

Primeira decisão editorial em 07.12.2001

Versão final em 14.05.2002

Aceito em 14.05.2002 